\title{
Syringomyelia: diagnosis and management
}

\section{Graham Flint}

\section{Correspondence to}

Mr Graham Flint, Department of Neurosurgery, Queen Elizabeth Hospital, Birmingham, UK; graham.flint@uhb.nhs.uk

Accepted 14 May 202 Published Online First 25 August 2021
D Check for updates

(c) Author(s) (or their employer(s)) 2021. No commercial re-use. See rights and permissions. Published by BMJ.

To cite: Flint G. Pract Neurol 2021;21:403-411.

\begin{abstract}
In the pre-MR era syringomyelia often presented late, as a crippling neurological disorder. Today, most cases are diagnosed earlier, with less pronounced deficits. We are therefore presented with new challenges, including understanding the significance of various presenting symptoms, knowing when surgery might help and being aware of other treatments that could benefit someone living with the effects of syringomyelia, or its underlying cause.
\end{abstract}

\section{INTRODUCTION}

The classical presentation of syringomyelia, with combined upper and lower motor neurone features and autonomic disturbances, is now seen only occasionally (table 1). High expectations on the part of the public in terms of early diagnosis, together with ready availability of MR imaging, have led to many more syrinx cavities being detected, which are frequently not diagnosed clinically, before the scan. This is understandable, given that most patients now present with little in the way of physical signs, with the notable exception of scoliosis in adolescents. There is also a poor correlation between the size of any syrinx cavity and the intensity of a patient's symptoms. Even large cavities can present with little more than patchy sensory loss and, perhaps, an absent reflex.

In the past, most syringomyelia cavities were seen in association with Chiari malformations. We now encounter more instances of both conditions in isolation but it remains difficult to discuss one without the other. Syringomyelia is the more enigmatic and scientifically challenging of the two conditions but awareness of Chiari among the public is much higher than it is for syringomyelia. (Typing Chiari into the standard Google search engine will generate 20 times more hits than will typing in syringomyelia; even Google Scholar generates ten times as many articles for Chiari than for syringomyelia). Patient campaign groups are far more active about Chiari than they are about syringomyelia and there are several dedicated Chiari centres in parts of the world, but no named syringomyelia units as such.

\section{CLASSIFICATION AND NOMENCLATURE}

Syringomyelia may be defined as the presence of abnormal, CSF-filled cavities within the adult spinal cord. This distinguishes the pathological condition from normal anatomical variants such as persisting embryological central canals in children, although pathological cavities also occur in children. Even in the fully matured nervous system we encounter several morphological forms, including prominent or dilated central canals, isolated cysts and spindles, and fully formed syrinx cavities (sometimes referred to as holocord syringomyelia). Consequently, several different terms have been applied and adopted to varying degrees. Hydromyelia is widely used to refer to a pathologically dilated central canal, in which the lining will be ependymal. Syringomyelia is reserved, by some, to identify cavities which dissect into surrounding cord tissue and are lined by glial cells. Radiologists commonly report narrow, centrally located and symmetrical cavities as hydromyelia, but eccentrically placed and all larger cavities as syringomyelia. The filling mechanism (see below) may have a bearing on such distinctions but the author's view is that all these morphological forms fit the definition given above and that syringomyelia remains the appropriate, all-inclusive term. Arguments about whether the plural should be syrinxes or syringes are of semantic interest only. (To aspirate CSF, the author uses a syringe, taken out of a box of syringes, not a syrinx, taken from a box of syrinxes. The attached, fine needle then enters a syrinx, not a syringe.)

Chiari malformations are also referred to by a number of different names and 


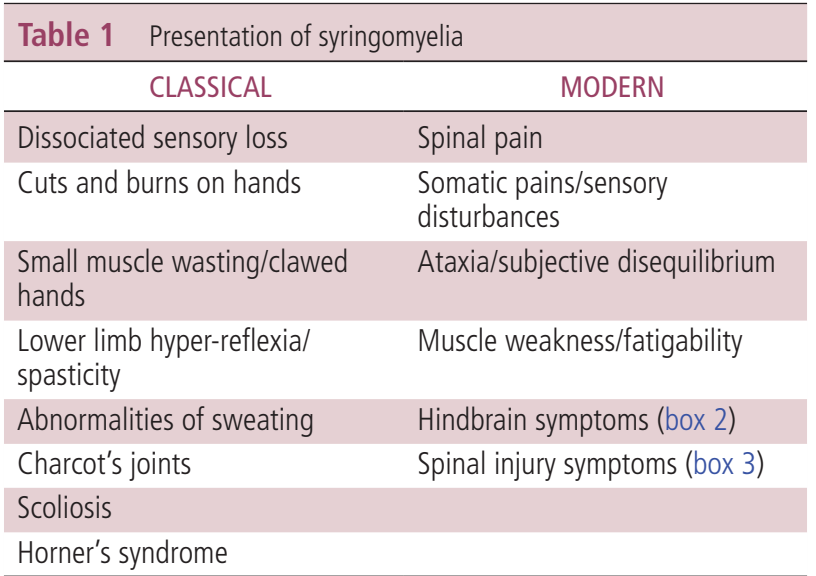

with several abbreviations adopted. Many neurologists still refer to an Arnold-Chiari malformation, a cause of confusion to some lay people, who ask who this person was. Abbreviations include ACM, CM or CM-I. Radiologists refer to tonsillar ectopia, simply describing scan appearances. Arguably the most appropriate term is hindbrain hernia, which at least gives some indication as to what the anatomical abnormality is. When it comes to the different types of Chiari malformation, conventional practice has been to use Roman numerals to differentiate between types. With the introduction of concepts such as Chiari 0 and Chiari 1.5 (figure 1) it might be better to use Arabic numbers, referring to types $0,1,1.5$ or 2 .
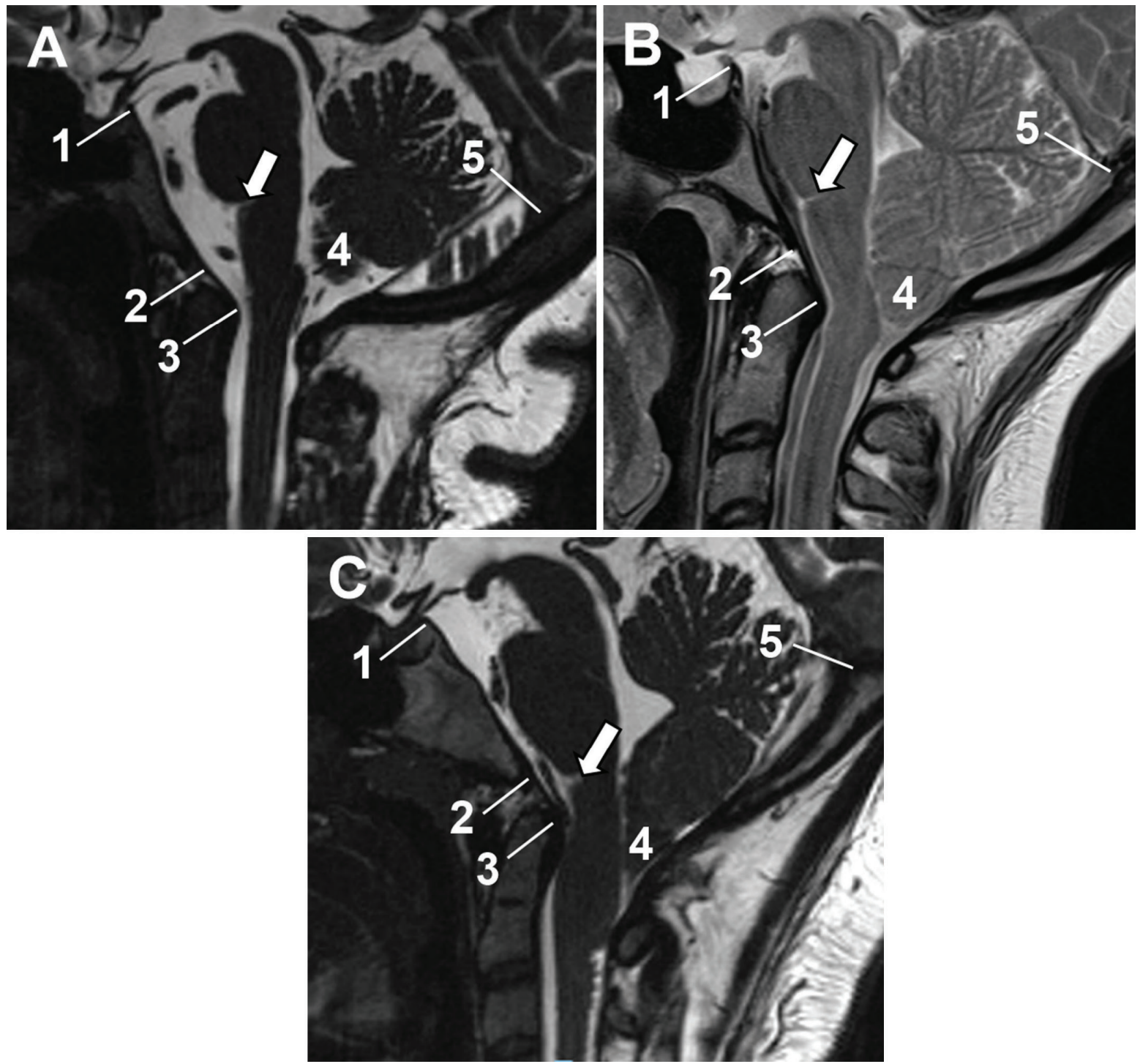

Figure 1 Chiari type 1.5. In this montage the following landmarks are indicated on each image: (1) posterior clinoid process, (2) inferior aspect of the clivus, (3) posterior aspect of the dens, (4) cerebellar tonsils and (5) torcula. The white arrow points to the ponto-medullary junction. Image A demonstrates normal posterior fossa anatomy, with the tonsils sitting comfortably above a normal cisterna magna. Image B is of a Chiari type 1 hindbrain hernia, where the tonsils occlude the cisterna magna but the cephalo-caudal position of other posterior fossa structures is normal. Image C illustrates Chiari type 1.5 in which the medulla is displaced caudally, as indicated by the position of the ponto-medullary junction. This type of hindbrain hernia may be associated with a low-lying conus. 


\section{Box 1 Classification of syringomyelia}

HINDBRAIN RELATED

Cerebellar tonsillar ectopias:

- Chiari 0: Low position but not herniated, with typical Chiari symptoms

- Chiari 1: Cerebellar tonsillar descent only

- Chiari 1.5: Tonsillar herniation +some medullary descent $^{*}$

- Chiari 2: Cerebellar+medullary descent, low inion, small posterior fossat

Arachnoid fibrosis for example, birth injury

Other for example, Paget's disease, rickets

\section{SPINAL PATHOLOGIES}

Post-haemorrhagic adhesions:

- Spinal injury

- Subarachnoid haemorrhage

Post-infective adhesions:

- Pyogenic,

- Tuberculous

Arachnoid cysts and webs

Tumour related for example, haemangioblastoma

\section{IDIOPATHIC}

Embryological remnants: normal calibre central canal Dilated central canals: as assessed on axial images Fully formed cavities: open cisterna magna: no Valsalval hindbrain symptoms

Glio-ependymal cysts: if located in conus then possibly related to cord tethering

${ }^{*}$ May be associated with a low-lying, tethered conus

†Accompanying spinal dysraphism and, frequently, hydrocephalus

Syringomyelia can develop as a result of other anatomical abnormalities, besides Chiari malformations and, when a cavity is identified, we look to locate a point where normal, free movement of CSF is impeded. This can occur at the craniovertebral junction or more caudally in the CSF channels. (Commonly, people refer to CSF spaces; this terminology may be appropriate in dissecting room specimens but, in life, the "spaces" are full of cerebrospinal fluid). Syringomyelia can therefore be considered under three broad aetiological headings: hindbrain-related, intraspinal pathology and idiopathic (Box 1).

\section{HINDBRAIN-RELATED SYRINGOMYELIA}

Chiari type 1 hindbrain hernias are thought to be abnormalities of mesodermal development, in which aberrant formation of the occipital somites leads to a mismatch between the volume of the posterior fossa and the cerebellum contained within it. Some form part of syndromic craniosynostoses (typically Crouzon's syndrome). Type 2 , in contrast, results from disordered neuroectodermal development, with
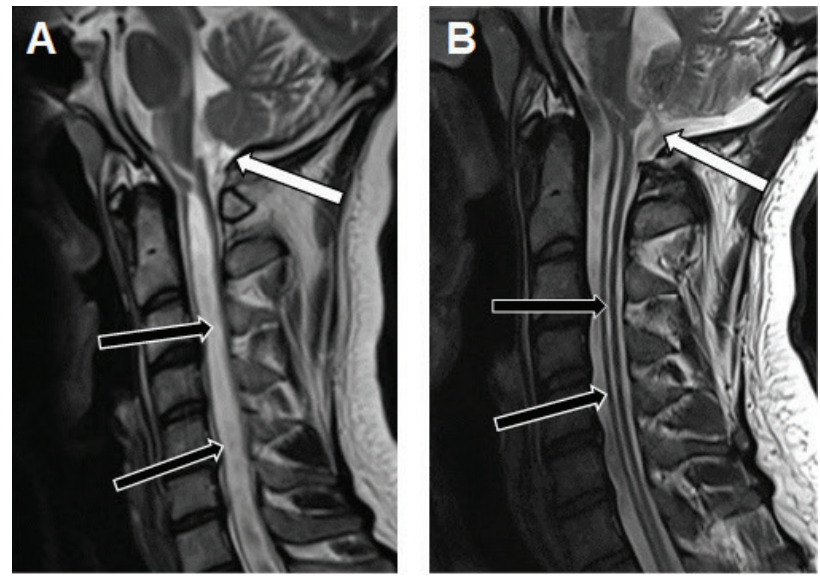

Figure 2 Birth injury. (A) A pronounced syrinx cavity is evident (black arrows) but the cerebellar tonsils are not herniated or occupying the cisterna magna to any degree (white arrow). When asked, the patient confirmed that his mother told him that his birth had been difficult, with a long labour and use of forceps, the latter having presumably caused a degree of intradural haemorrhage in the posterior fossa. (B) Extensive arachnoid scar tissue was encountered during surgery but an adequate channel for CSF flow could be created (white arrow), with resultant collapse of the syrinx cavity (black arrows).

failed closure of the neural tube causing spina bifida and, usually, hydrocephalus. An occasional cause of obstructed CSF movement at the craniovertebral junction is arachnoid scar tissue, formed as a result of a birth injury. A syrinx cavity of any prominence, seen in the absence of any tonsillar herniation, requires a birth history to be obtained, if possible (figure 2). Other uncommon causes of impeded CSF movement at the craniovertebral junction include bone thickening and bone softening disorders affecting the skull base, such as rickets and Paget's disease of bone.

Hindbrain hernias, as radiological appearances, are not an homogeneous group. In the first place, it is vital to distinguish them from acute tonsillar pressure cones. Less rapidly growing posterior fossa masses have also been known to cause tonsillar impaction and syrinx formation. Chronically raised intracranial pressure from other causes, in particular idiopathic intracranial hypertension, can also produce radiological appearances that mimic Chiari type 1. (Most surgeons now also counsel against using lumbar puncture to diagnose idiopathic intracranial hypertension in the presence of herniated cerebellar tonsils, particularly as intracranial pressure monitoring can now be carried out routinely, although with about a $1 \%$ risk of serious complications.)

In addition to pressure from above, "suction" from below can cause tonsillar herniation. Spontaneous intracranial hypotension is increasingly recognised as a cause of hindbrain herniation, although locating the CSF fistula, if indeed it persists, remains a challenge. Lumbo-peritoneal shunts can, similarly, cause 
the cerebellar tonsils to herniate through the foramen magnum.

The conventional radiological criteria for diagnosing Chiari malformations are being challenged. Up to $3 \mathrm{~mm}$ of descent below McRae's line (drawn, on plain X-rays, mid-sagittal CT or MR images, from the tip of the clivus to the posterior rim of the foramen magnum) is regarded as being within the range of normal, whereas $5 \mathrm{~mm}$ or more is seen as abnormal. Such measurements are, however, of limited value, particularly as there is a poor correlation between the degree of tonsillar descent and the magnitude of a patient's symptoms. Further, a greater degree of tonsillar descent is acceptable as being normal in children and young adults, as compared with older people. The amount of crowding of the foramen magnum, as seen on axial images, is probably of greater significance, although it is less easily quantifiable. These issues are a common cause of consternation among patients who, referring to the internet, learn that their symptoms could be caused by their recently identified "Chiari", only to be told, by their neurologist or neurosurgeon, that the finding is incidental. One approach, in trying to resolve such matters, is the use of cine-MRI flow studies although, while to and fro' movement of CSF with cardiac systole may be well seen, bulk displacement brought on by Valsalva is not easily demonstrated.

The main clinical clue that a hindbrain hernia is the cause of symptoms is the nature of the patient's headaches. Typical Valsalva-induced headaches suggest that there is pressure dissociation across the craniovertebral junction. Pre-MR era investigations, involving oil-based contrast media, revealed that CSF is driven from the spinal theca into the cranial compartment during Valsalva. ${ }^{1}$ With a normal state of anatomy, CSF simply returns when physical straining ceases. Herniated cerebellar tonsils, however, create a valve mechanism, briefly trapping the excess volume of CSF in the head, causing headache. A carefully taken history, from a good witness, may well reveal that the typical, intense headache comes on, not during the straining, but immediately afterwards, for example, getting up from bending forwards.

A large variety of other symptoms can be associated with Chiari type 1 malformations, independent of any arising from associated syringomyelia (Box 2). These include non-specific headaches, which are often phenotyped as migraine. Occipital headaches can be accounted for by pressure on the basal dura, which is innervated by the upper cervical nerves. Other symptoms can be attributed to pressure placed on brainstem nuclei, or on ascending and descending long tracts at the cervicomedullary junction. Memory loss and "brain fog" are common complaints but are more difficult to explain. Whether the full list of symptoms should be recognised as a "cranio-cervical syndrome" is debatable. Both Oxford and Webster dictionaries specify that, in order to constitute a syndrome, symptoms
Box 2 Symptoms of Chiari malformation

HEADACHES
Valsalva-induced
Occipital
Generalised
BULBAR
"Dizziness"
Tinnitus/hearing loss
Dysphagia, dysphonia
- Diplopia/oscillopsia *
LONG TRACTS
- Ataxia/subjective sense of imbalance
- Subjective weakness/fatigue
Somatic pains and sensory disturbances
UNCERTAIN ORIGIN
"Blackouts"
*Asympor memory or "brain fog"
with acuity or visual fields suggest underlying intracranial hyper-
tension
tCentral, from brain stem compression, or obstructive resulting
from reduced innervation of pharyngeal muscles

must occur together, and this is far from the case in many patients with Chiari. With Chiari type 2, bulbar symptoms may dominate and, in neonates, laryngeal palsies can be life threatening.

\section{SPINAL AND POST-TRAUMATIC SYRINGOMYELIA}

Obstruction to CSF movement in the spinal canal is most often the result of scar tissue formation in the arachnoid plane. (This anatomical state is commonly referred to as "arachnoiditis" but this is a misnomer because the original inflammatory process will have subsided by the time the scar tissue has matured; use of the term "post-arachnoiditic adhesions" would be more accurate). In the absence of trauma this can result from previous infection (pyogenic or tuberculous), or haemorrhage. The underlying pathology in such cases is usually clear from the history. Use of oil-based contrast media for myelography was, at one time, a cause of spinal arachnoid adhesion formation but far fewer cases now come to light. Arachnoid cysts and webs are also encountered, without any obvious cause. They usually create "hydraulic myelopathy", from raised CSF pressure outside the cord, but occasionally also lead to syrinx formation. Intramedullary tumours can produce syrinx cavities, either by extension of their cystic component (most often seen with hemangioblastoma) or by cord expansion obstructing normal CSF movement in the spinal theca. Whether spondylotic stenosis of the cervical canal can cause syrinx development is a moot point. Given the frequency 


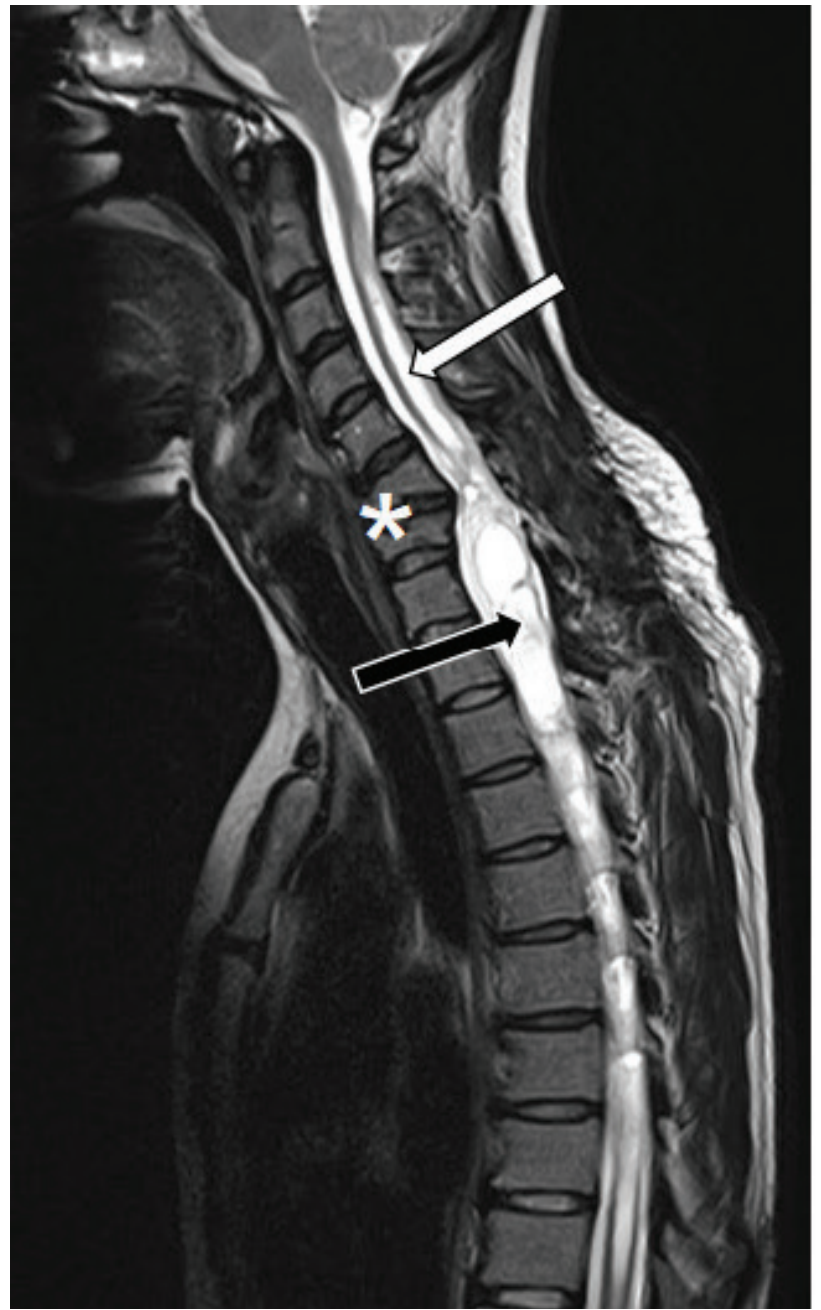

Figure 3 Post-traumatic syringomyelia. Extensive cord damage at the $C 6 / 7$ vertebral levels (asterisk) means that cord transection is functionally complete. Surgery aimed at decompressing the tense syrinx cavity below this level (black arrow) may not produce any functional gain but intervention may be indicated if the cavity propagating above the injury (white arrow) is threatening to cause functional loss in the upper limbs

with which such narrowings develop with advancing years, it is notable how seldom we see syringomyelia in association.

Post-traumatic syringomyelia (figure 3 ) is a prime example of something quite literally adding physical insult to an existing injury. Syringomyelia remains uncommon in the population as a whole but is a frequent development following spinal cord injury. The radiological incidence is as high as 1 in 5, with symptomatic cavities developing in 1 in 20 of all spinal cord injury victims. ${ }^{2}$ Clearly, upward propagation of a syrinx, in an already paraplegic individual, threatens to take away even more of his or her independence. The latent interval between the original injury and a posttraumatic syrinx coming to light ranges widely, from a few months to many decades. Various studies have looked at what factors might influence the likelihood

\section{Box 3 Presentation of post-traumatic syringomyelia}

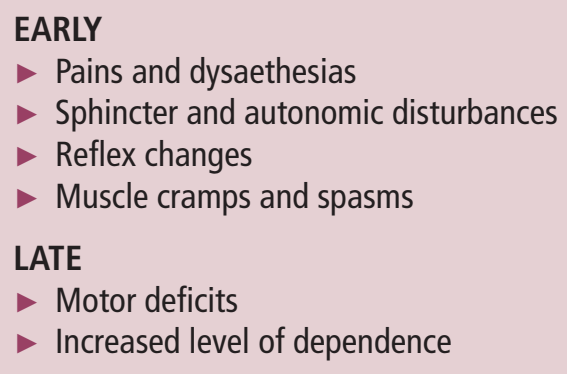

of syringomyelia developing. Findings have varied and it remains impossible to predict who might be at greatest risk. It is therefore sensible to offer spinal cord injury patients life-long follow-up, with interval imaging should there be any change in their symptoms or signs (Box 3).

An issue of debate is whether early surgical intervention to decompress the cord, to stabilise the acutely injured spine or to correct any vertebral deformity, might lessen the likelihood of a post-traumatic syrinx cavity forming. Published papers give conflicting results ${ }^{3}$ but, given that intradural scar tissue formation is the likely underlying cause of cavity formation, the correction of any extradural narrowing of the spinal canal would seem unlikely to be of benefit.

\section{IDIOPATHIC SYRINGOMYELIA}

It could be argued that there is no such thing as idiopathic syringomyelia and that a more diligent search is required, to locate a point of obstruction in the CSF pathways (perhaps the term "cryptopathic" would be more appropriate). Certainly, some arachnoid webs can be difficult to detect but subtle features can usually be seen on high resolution T2 or cine-MR imaging, ${ }^{4}$ or on myelographic studies. With larger "idiopathic" syrinxes contrasted studies are needed, to exclude an underlying intrinsic cord tumour. Such lesions may not reveal themselves on initial studies so an interval contrasted scan may be a wise precaution. Smaller, so-called hydromyelia cavities (figure 4) presumably result from some other, as yet unidentified disturbance of CSF dynamics. Prominent central canals are often dismissed as embryological remnants. They may look like such on sagittal images but axial views often show them to have a transverse diameter up to a third that of the cord. Dismissing such collections as anatomical variants does not give adequate consideration to their possible filling mechanism.

The obvious question is whether small, hydromyelia cavities can be responsible for a patient's symptoms. In the author's experience, for the most part these consist of somatic pains and sensory disturbances, with motor, sphincter and autonomic disturbances being less common. If the cord segments occupied by the syrinx match the clinically involved dermatomes 


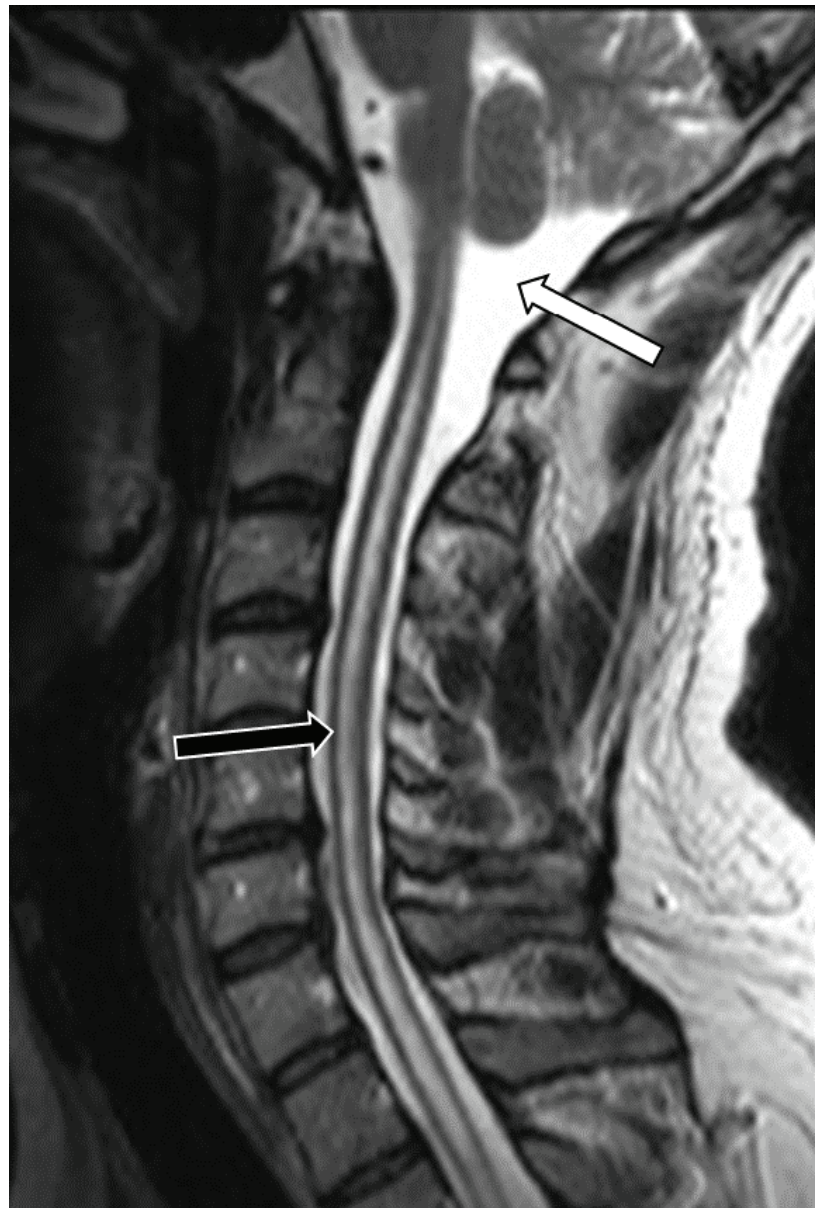

Figure 4 Idiopathic syringomyelia. This mid-sagittal, T2 MR image reveals an extensive, although not unduly tense syrinx cavity (black arrow). It seems unlikely that there will be any obstruction to cerebrospinal fluid movement across the craniovertebral junction (white arrow) and the label "idiopathic" syringomyelia is probably appropriate in this case. With low-lying tonsils occupying a less prominent cisterna magna, and in the presence of pressure dissociation headaches, the term Chiari type 0 might be applied instead.

or myotomes, then the answer may be yes. Although surgical solutions (see below) are limited, an openminded approach may be wiser than simply disregarding the radiological finding and leaving the patient feeling dismissed.

\section{THE FILLING MECHANISM}

The most fascinating and challenging aspect of syringomyelia, from the scientific perspective, is comprehending how the cavities form and then propagate. Some understanding is clearly needed if we are to place any treatment on a rational basis. Any theory needs to explain syrinx formation resulting from impaired CSF flow at the craniovertebral junction, from obstructed CSF movement lower down the spine, or when there no obvious blockage in CSF channels. It also needs to account for why some cavities progress and others enter a state of hydrodynamic equilibrium. Also, why do some syrinxes propagate in a cephalad direction, some caudally and some in both directions? Why do most syrinxes stop at the cervicomedullary junction but some extend into the brain stem and, very occasionally, into the corona radiata?

The early theories of Gardner and Angel $^{5}$ and Williams, ${ }^{6}$ still widely quoted, both assumed that hindbrain-related syrinx cavities filled via the obex and central canal. Gardner thought that arterial pulsation provided the driving energy whereas Williams considered that Valsalva-induced, venous pressure waves were responsible. Early operations therefore involved plugging the obex with muscle. In reality, it was the surgical exposure, needed to gain access to the fourth ventricle, which provided the cure, by creating a channel which permitted free CSF movement across the craniovertebral junction.

Ball and Dayan later suggested that CSF penetrated cord parenchyma via perivascular spaces, ${ }^{7}$ a proposal supported by more recent work. ${ }^{8}$ Oldfield and others, then identified a piston-like action of the herniated tonsils, acting on a trapped column of spinal CSF, thereby driving CSF into the cord. ${ }^{9}$ Perivascular channels must also create a valve-like mechanism, otherwise how do we account for the high pressures recorded inside syrinx cavities. ${ }^{10}$ There may, nevertheless, still be a role for filling via the obex and central canal in some cases (figure 5).

A further puzzle is an apparent dichotomy, in that Chiari patients present either with or without a syrinx cavity and that those with uncomplicated Chiari seldom go on to develop syringomyelia. Veterinary colleagues have made similar observations in Cavalier King Charles Spaniels, all of which have a Chiari-like malformation but only about half of which form syringomyelia. (Dogs do not have cerebellar tonsils but Cavaliers, in common with some other toy breeds, have cerebellar tissue herniated into their upper necks, a consequence of their having small posterior fossas). One of their studies suggested that the efficiency of cerebral venous drainage may have some bearing on this. ${ }^{11}$ In human medicine the role of sagittal sinus pressures is now also being investigated, as a possible contributor to tonsillar herniation. This "moving upstream" philosophy may provide opportunities for less invasive, endovascular methods of treatment. There have certainly been reports of hindbrain-related syringomyelia resolving after cerebral venous sinus stenting. ${ }^{12}$

The author's current, working concept is of two types of energy waves acting on a CSF column that extends from below the tentorium, down to the sacral theca. These consist of regular, low-energy, arterial pressure waves and intermittent, high-energy, venous waves. The former probably provide the syrinx filling mechanism. The latter account for the classical Chiari headaches.

\section{MANAGEMENT}

Large, symptomatic syrinx cavities, with an obvious underlying cause such as a Chiari malformation, invite surgical correction. As with chronically enlarged cerebral ventricles, however, intervention is far from 


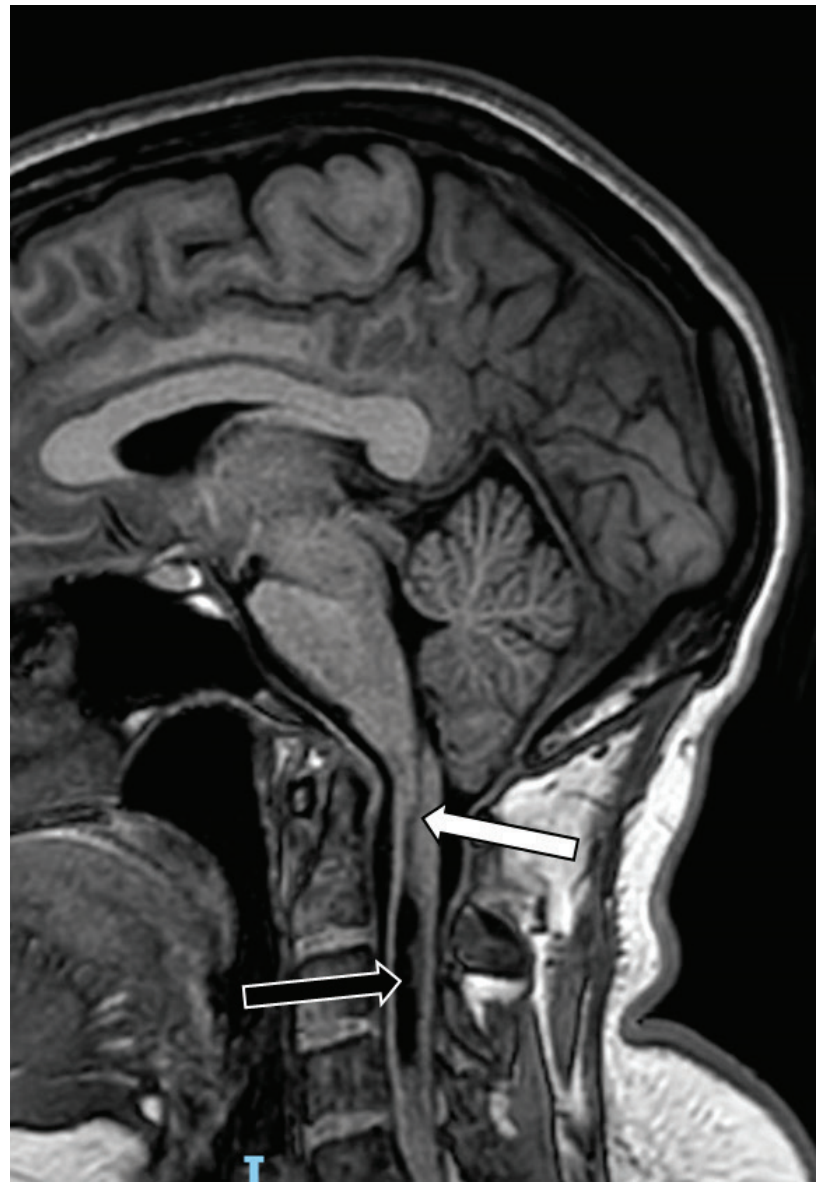

Figure 5 Communicating syringomyelia. Although the currently most widely promoted view is that syrinx cavities fill via perivascular spaces, images such as this T1 sagittal MR scan of a syrinx cavity (black arrow) suggest that filling may be via a communication between the obex and the central canal in some cases (white arrow)

mandatory, something that is well appreciated now that we detect increasing numbers of cavities on imaging. Patients may have little in the way of physical disability, even in the presence of an extensive syrinx cavity. The natural history of syringomyelia varies from case to case, for reasons that are not clear. Spontaneous collapse of syrinx cavities does occur (figure 6), although not sufficiently often as to be relied on as a routine form of treatment. Syringomyelia is seldom a life-threatening condition although, very occasionally we may encounter a patient who is decompensating quite rapidly. Chiari type 2 in children can also sometimes present as fulminating bulbar failure, requiring emergency intervention. In most cases there is time to assess, counsel and arrange follow-up for the patient. Importantly, even when surgery is able to induce a syrinx cavity to collapse, pain and somatic sensory disturbances may well persist; the odds of gaining relief from such symptoms are about evens, in an individual case. ${ }^{13}$ Surgery does, however, have a place for syringomyelia that is clearly producing progressive motor disability, particularly if this is associated with
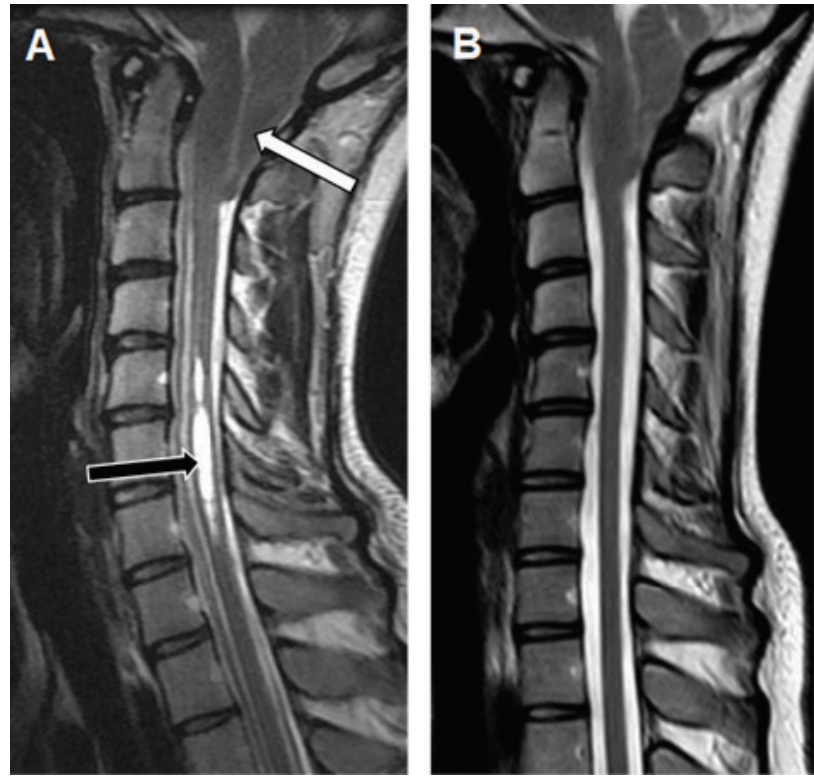

Figure 6 Spontaneous collapse. This patient presented, in her mid 20s, with pressure dissociation headaches, upper limb paraesthesias and a subjective sense of ataxia. Craniovertebral decompression was initially planned but her symptoms then improved without intervention. (A) Pronounced tonsillar herniation, (white arrow), with resultant syrinx formation (black arrow). (B) Corresponding images obtained a little over 2 years later.

extension of the cavity on serial imaging. Decompression of a syrinx may also arrest or even reverse progression of adolescent scoliosis. ${ }^{14}$ Whether surgery for uncomplicated Chiari does so is, at present, much less certain.

When it comes to Chiari malformations without an associated syrinx, there is even more reason to adopt a conservative approach, in the first instance at least. Chiari, left untreated, is unlikely to cause an adult patient to come to harm, although children may be more vulnerable in, for example, road traffic collisions. Undoubtedly, craniovertebral decompression can be life-changing for the good but it can, of course, be lifechanging for the bad. Hazards of surgery include acute hydrocephalus, CSF leakage, bacterial meningitis, chemical meningitis and, rarely, acute brain swelling. At the very least it is an uncomfortable operation. Neurosurgeons will emphasise all these points to their patients, being, in the UK at least, fully aware of the implications of Court rulings such as Montgomery. ${ }^{15}$ These factors, plus our appreciation of the relatively high incidence of tonsillar ectopia seen on cranial MR scans, have led neurosurgeons to be cautious in offering surgery, or even attributing a patient's symptoms to such findings in the first place. Despite this, some patients may press for surgery, perhaps regarding their surgeon as being risk averse. We should see this as a clear indicator of the patient's distress and their need for further explanation and counselling. Otherwise there is a risk of that person turning to social media 


\section{Box 4 Treatment options for syringomyelia}

- Conservative management

- Create a conduit for free movement of CSF

- Catheter drainage of the syrinx cavity

- Lowering the overall CSF pressure

for inexpert "advice" and, on occasions, raising money to fund costly surgery overseas.

If we do look to intervene surgically, there are three ways of trying to induce a syrinx cavity to collapse (Box 4). The ideal is to create a continuous column of CSF, extending from the posterior fossa down to the sacral thecal sac, along which arterial and venous pressure waves can disperse normally, such that the fluid is no longer being driven into the cord substance. This is most often achievable by craniovertebral decompression for hindbrain-related syringomyelia. The same operation can effectively relieve the pressure-dissociation headaches of uncomplicated Chiari malformations, although the response of other symptoms is less predictable. ${ }^{16}$ Conduits, permitting normal CSF movement to occur, can also be created to collapse post-traumatic syrinxes, provided the arachnoid fibrosis is well localised. Post-infective scar tissue, particularly post-tuberculous adhesions, tends to be more extensive and less amenable to this approach. In such cases, or when an initial attempt to create a conduit has failed - usually because of re-obstruction of the CSF channels by post-operative scar tissue - the better option may be direct drainage of the syrinx cavity. This approach, however, has two drawbacks. First, a myelotomy is required, for insertion of the drainage catheter. This will inevitably lead to some loss of dorsal column function and midline myelotomies should certainly be avoided, lest they cause loss of perineal sensation. Incisions just medial to the dorsal root entry zone, in the thoracic cord, are less likely to produce any functional deficit. The second drawback is that, as with any CSF diversion operation, catheters may block with time. Long term, about half of all syrinx drainage shunts fail. ${ }^{17}$ On the other hand, direct drainage usually decompresses the cavity straight away, with early radiological and clinical improvement. (We aim to decompress, not "deflate" syrinx cavities; they contain fluid, not flatus). The receptacle for the syrinx fluid is a matter of the individual surgeon's preference, be it the plural cavity, the peritoneum or another point in the spinal theca where CSF flow is unimpeded.

If other surgical measures fail, a remaining option is to lower the overall CSF pressure with some form of CSF diversion operation. The rationale is that, by reducing the pressure, or "turgidity", in the spinal theca, the energy of arterial and venous pressure waves will be lessened, with consequent reduced filling of the syrinx. In the presence of hydrocephalus, hindbrain hernias are best managed with a ventriculoperitoneal shunt in the first instance. Craniovertebral decompression will likely make the hydrocephalus worse, whereas a shunt operation avoids such hazards and may prove to be all that is needed to resolve the patient's symptoms. There are also case reports of hydrocephalus, in association with hindbrain hernia and syringomyelia, being treated by endoscopic third ventriculostomy, with resultant collapse of the syrinx. ${ }^{18}$

In the absence of an identifiable point of obstruction to CSF movement, treatment of most idiopathic syrinxes is mainly conservative, with explanation, reassurance and pain management. Unlike many chronic pain syndromes that we encounter, the somatic pains seen with syringomyelia are neurogenic in origin and provide an ideal clinical model for study. ${ }^{19}$ Opiate, non-steroidal and other analgesics are unlikely to be effective and neuro-modulatory drugs are more appropriate. Acupuncture may benefit some. So may physiotherapy and occupational therapy, by helping the individual compensate for his or her neurological impairment.

\section{UNCERTAINTIES AND CONTROVERSIES}

Despite the ease with which the diagnosis of syringomyelia can now be confirmed, and notwithstanding our better understanding of the filling mechanisms of syrinx cavities, there remain many uncertainties and several controversies regarding the condition. Surgeons still debate the best method of operating, in particular extent of decompression and whether or not dural grafts should be used. The place for anterior decompression or internal fixation in the presence of basilar invagination is open to discussion. ${ }^{20}$ Preoperative assessment practices vary, with some surgeons requesting cerebral venography and others routinely performing intracranial pressure monitoring.

A link between Chiari malformations and EhlersDanlos hypermobility is another subject of current discussion, including a possible relationship with postural orthostatic tachycardia syndrome, mast cell activation syndrome, and even irritable bowel syndrome. The role of surgery for low-lying cords in relation to Chiari also remains unresolved, particularly when it comes to "functional" tethering of an anatomically normal conus.

Blackouts, while seldom the sole presenting feature, are a not uncommon component symptom of hindbrain hernias. They may understandably raise concerns about brainstem compression, particularly if epileptic and cardiac causes have been excluded and especially if they are precipitated by Valsalva. Otherwise, their underlying mechanism is often unclear and yet most cease after decompression surgery. $^{16}$

Obstetric aspects of syringomyelia and Chiari form an important topic, over which views have recently changed. $^{21}$ Normal vaginal delivery is unlikely to 
cause harm to the mother with Chiari, although caution should be exercised with using epidural anaesthesia, lest inadvertent dural puncture converts a Chiari into a tonsillar pressure cone. The presence of large syrinx cavities may also dictate a need for elective Caesarean section. Clearly, a multi-disciplinary team approach is required for individual cases, with input from obstetrics, anaesthetics, neurology and neurosurgery, as well as ophthalmology if indicated.

\section{CONCLUSIONS}

Syringomyelia and cerebellar tonsillar ectopias are now all too easily revealed on imaging, such that the challenge is to distinguish the symptomatic lesion from the incidental finding. When not displaying any physical signs, patients reporting a plethora of neurological symptoms may, understandably, feel victims of a "hidden" disorder. Some even adopt titles such as "Chiari warriors", a label revealing the emotional burden that many carry. Our duty, as doctors, is to listen to and believe our patients. We must take the time to explain matters, apologising for our own deficiencies in understanding these enigmatic disorders. We always aim to "do no harm" but

\section{Key points}

Syringomyelia is a disorder of CSF circulation.

- Regular, systolic arterial energy waves cause syrinx cavities to fill; venous pressure waves cause the pressure dissociation headaches typical of Chiari.

- Distinguish between a chronic hindbrain hernia and an acute tonsillar pressure cone.

- There is a poor correlation between the degree of hindbrain herniation and the severity of a patient's symptoms.

- Many syrinx cavities enter a state of hydrodynamic equilibrium and may be managed conservatively; patients may have little in the way of disability, in the presence of an extensive syrinx cavity.

- Syringomyelia is rarely a life-threatening condition; Chiari malformations, left untreated, are unlikely to cause an adult patient to come to harm.

- Pregnancy can usually be managed along normal obstetric lines.

- Pains and somatic sensory disturbances remain an unsolved problem for many patients with syringomyelia.

\section{Further reading}

Tubbs RS, Oakes WJ. The Chiari malformations. New York: Springer, 2013.

- Flint G, Rusbridge C. Syringomyelia: a disorder of CSF circulation. Berlin: Springer, 2014. we must also avoid leaving our patient feeling not believed and dismissed.

Acknowledgements The author is indebted to Nick Haden, Consultant Neurosurgeon, Tom Hayton, Consultant Neurologist and Julie Millward of the Ann Conroy Trust (www.annconroytrust.org), each of whom reviewed and made helpful suggestions about this manuscript.

Funding The authors have not declared a specific grant for this research from any funding agency in the public, commercial or not-for-profit sectors.

Competing interests None declared.

Patient consent for publication Not required.

Provenance and peer review Commissioned; externally peer reviewed by George Malcolm, Bristol, UK.

\section{REFERENCES}

1 Williams B. In: syringomyelia: current concepts in diagnosis and treatment. Baltimore: Williams \& Wilkins, 1991: pp 59-90.

2 Wang D, Bodley R, Sett P, et al. A clinical magnetic resonance imaging study of the traumatised spinal cord more than 20 years following injury. Paraplegia 1996;34:65-81.

3 Carroll AM, Brackenridge P. Post-Traumatic syringomyelia: a review of the cases presenting in a regional spinal injuries unit in the North East of England over a 5 -year period. Spine 2005;30:1206-10.

4 Ben Ali H, Hamilton P, Zygmunt S, et al. Spinal arachnoid web-a review article. J Spine Surg 2018;4:446-50.

5 Gardner WJ, Angel J. The mechanism of syringomyelia and its surgical correction. Neurosurgery 1959;6:131-40.

6 Williams B. The distending force in the production of "communicating syringomyelia". The Lancet 1969;294:189-93.

7 Ball M, Dayan A. Pathogenesis of syringomyelia. The Lancet 1972;300:799-801.

8 Stoodley MA, Brown SA, Brown CJ, et al. Arterial pulsation-dependent perivascular cerebrospinal fluid flow into the central canal in the sheep spinal cord. J Neurosurg 1997;86:686-93.

9 Oldfield EH, Muraszko K, Shawker TH, et al. Pathophysiology of syringomyelia associated with Chiari I malformation of the cerebellar tonsils. Implications for diagnosis and treatment. $J$ Neurosurg 1994;80:3-15.

10 Milhorat TH, Capocelli AL, Kotzen RM, et al. Intramedullary pressure in syringomyelia: clinical and pathophysiological correlates of syrinx distension. Neurosurgery 1997;41:1102-10.

11 Schmidt MJ, Ondreka N, Sauerbrey M, et al. Volume reduction of the jugular foramina in Cavalier King Charles Spaniels with syringomyelia. BMC Vet Res 2012;8:158.

12 Chung CY, John S, Luciano MG, et al. Reduction in syrinx size and severity after venous sinus stenting in a patient with pseudotumor cerebri and Chiari malformation: technical case report. Oper Neurosurg 2016;12:E197-201.

13 Milhorat TH, Kotzen RM, Mu HT, et al. Dysesthetic pain in patients with syringomyelia. Neurosurgery 1996;38:940-7.

14 Eule JM, Erickson MA, O'Brien MF, et al. Chiari I malformation associated with syringomyelia and scoliosis: a twenty-year review of surgical and nonsurgical treatment in a pediatric population. Spine 2002;27:1451-5. 
15 Chan SW, Tulloch E, Cooper ES, et al. Montgomery and informed consent: where are we now? BMJ 2017;357:j2224.

16 Pepper J, Elhabal A, Tsermoulas G, et al. Symptom outcome after craniovertebral decompression for Chiari type 1 malformation without syringomyelia. Acta Neurochir 2021;163:239-44.

17 Batzdorf U, Klekamp J, Johnson JP. A critical appraisal of syrinx cavity shunting procedures. J Neurosurg 1998;89:382-8.

18 Hayhurst C, Osman-Farah J, Das K, et al. Initial management of hydrocephalus associated with Chiari malformation type
I-syringomyelia complex via endoscopic third ventriculostomy: an outcome analysis. J Neurosurg 2008;108:1211-4.

19 Hatem SM, Attal N, Ducreux D, et al. Clinical, functional and structural determinants of central pain in syringomyelia. Brain 2010;133:3409-22.

20 Klekamp J. Treatment of basilar invagination. Eur Spine J 2014;23:1656-65.

21 Roper JC, Al Wattar BH, Silva AHD, et al. Management and birth outcomes of pregnant women with Chiari malformations: a 14 years retrospective case series. Eur J Obstet Gynecol Reprod Biol 2018;230:1-5. 